\title{
Multi-Layer Project Cycle Management MODEL FOR COMPLEX PROJECTS
}

\author{
KAFOL, C.
}

Abstract: This paper presents the project management method which is designed to improve efficiency of the project implementation and improve approach to project funding. Based on a multiple case study research and its findings, upgraded existing project management approach has been introduced. The aim of this research is to propose an upgraded project cycle management model which introduces modern project management principles and tools to improve project results. Using stakeholder theory and modern management approaches such as stakeholder theory, long term project monitoring, "out-of-the-box" approach and other, this paper introduces new and upgraded Project Cycle Management methodology that will optimize project results, improve funding approach and enable sustainable system for project managing of complex projects.

Key words: Project Cycle Management, international development projects, project management, systems methodology, stakeholder theory
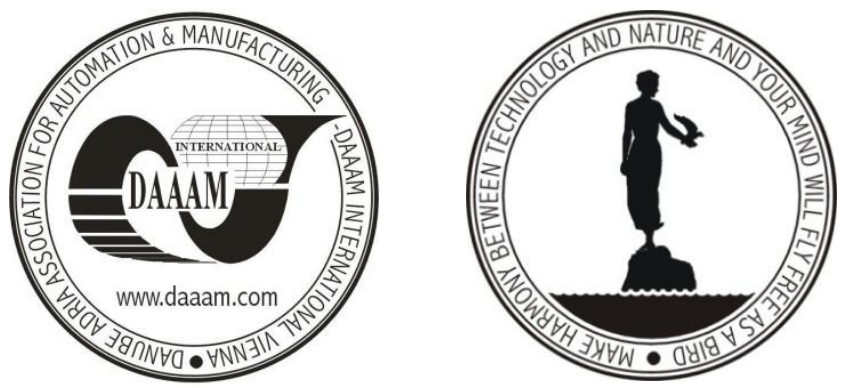

Authors' data: $\mathrm{Ph} \mathrm{D}$ Kafol C[iril], Telekom Slovenije, d.d., ONE (Skopje, Macedonia), Cigaletova 15, SI - 1000 Ljubljana, Slovenia, European Union Email: cirilkafol@gmail.com

This Publication has to be referred as: Kafol, C[iril] (2014). Multi-Layer Project Cycle Management Model for Complex Projects, Chapter 23 in DAAAM International Scientific Book 2014, pp.279-294, B. Katalinic (Ed.), Published by DAAAM International, ISBN 978-3-901509-98-8, ISSN 1726-9687, Vienna, Austria DOI: $10.2507 /$ daaam.scibook.2014.23 


\section{Introduction}

A new era is characterized by a multitude in the widest sense starting with population through society demands to solutions for products, people and events, innovation, flexibility, quality costs, productivity and ultimately the scope of market needs. All this needs to be reconciled in an effective manner in order to achieve the result that takes society to a new phase of growth and development. Information technology is recognized as a tool for enhancement of productivity and connectivity, and right of all people to access information and trends. The power of this wave of change brought on by information technology can be seen in the emergence of the information society, whose intensity of changes successfully keeps up the pace with the industrial revolution and the changes it brought about. From steam engines to the Ford assembly line, changes were inspired by technological solutions provided by individuals and groups of people that were physically close.

Project complexity in a new society increases fast; therefore, project management models need to be constantly developed to cope with the change.

The purpose of this paper is to study the interconnection between funding and development of information society and propose improved project management model that will enhance the project results efficiency and improve the efficiency of project funding.

The questions that we have asked in the study were:

1) Is the EU funding influencing positively the process of forming the information society?

2) Is it possible to improve the project methodology and approach?

We have performed a multiple case study research (Yin, 2011) involving an EU funded projects and are using modern management principles described in PMBOK 2013. We introduced the stakeholder theory (Laplume et al., 2008), long- term project evaluation and "out of the box" approach to develop a multi-layer project management model.

The aim of this research is propose an upgraded project cycle management model which introduces modern project management principles and tools to improve project results.

\section{Project cycle management model}

The European Commission adopted (as the principal body in charge of the implementation of the cohesion policy and management of nations' funds) the term Project Cycle Management in 1992 as a primary set of tools for project development and management, based on a logical framework approach.

The generic project cycle consists of five phases (Figure 1): Programming, Identification, Formulation, Implementation and Evaluation (European Commission, 2003). Arrows show the influence flow from the Evaluation to the Identification phase. Feedback from the Evaluation Phase corrects the data in the Project 
Identification Phase. This represents one of the crucial difficulties due to late impact into early project phases.

This division of the cycle in five stages provides minimum conditions for effective project preparation, implementation and evaluation. The project cycle starts with identification of the idea and its development into a work plan that can be implemented and its effectiveness evaluated. The project cycle should ensure that all stakeholders are consulted, thus making relevant information available.

Figure 1 gives overview of the generic Project Management Cycle.

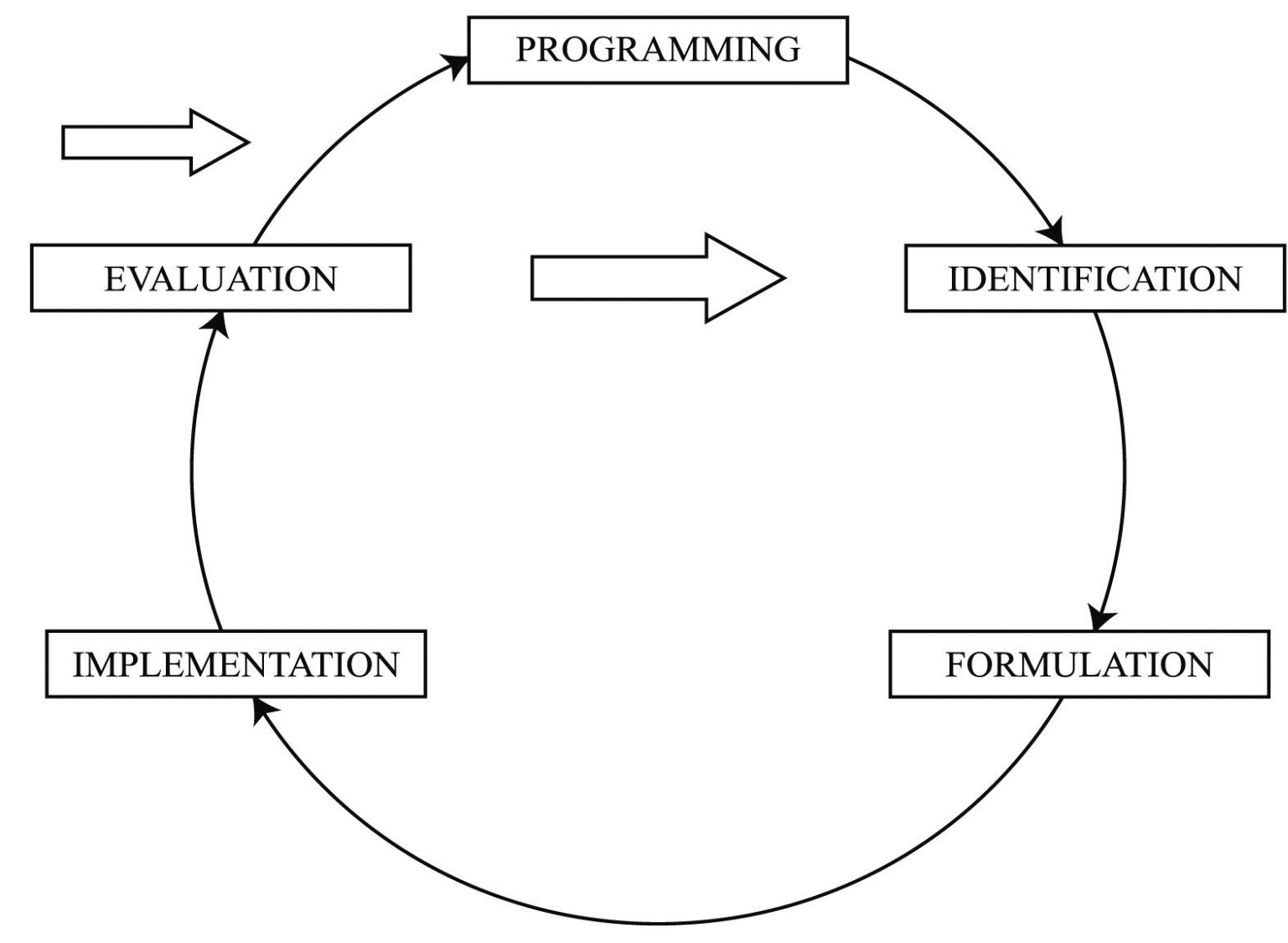

Fig. 1. Generic project management cycle

This division of the cycle in five stages provides minimum conditions for effective project preparation, implementation and evaluation. The project cycle starts with identification of the idea and its development into a work plan that can be implemented and its effectiveness evaluated. The project cycle should ensure that all stakeholders are consulted, thus making relevant information available.

The cycle is characterized by key decision- making, as well as demand for information and responsibilities at each stage.

The pursuit of progress characterizes all phases. This means that any previous stage must be successfully completed in order to ensure the success of the next one.

During the programming phase, the national and sectoral levels are analyzed in order to determine the problems, constraints, obstacles and possibilities. The idea 
behind this is to identify and to align basic objectives and sectoral priorities for cooperation development and the achievement of real and achievable program framework within which projects can be selected and exported. The next i.e. the identification phase involves consultation with potential customers of each stock, analysis of encountered problems and identification of possibilities that can influence these problems. LFA (Logical Framework Approach) is an instrument for analysis and management, used by majority of donor agencies, international NGOs, and a large number of partner governments for management of development projects (Sector for Programming and Management of EU Funds and Development Assistance).

The logical framework summarizes the objectives, activities, assumptions, indicators and verification factors, with purpose of measuring and reporting on the achievement of project objectives (Biggs \& Smith, 2003). All these tools, however, were not able to fully close the gap between the delayed involvement of end users in the project implementation and the project results.

When it comes to measuring the success of international development (ID) projects, failure is often a rule rather than an exception. Logical Framework Approach (LFA) is the most widely used tool for management of international development projects, but has shown significant shortcomings over the years. The most common weakness referred to in the literature concerns the monitoring and evaluation phase of the project life cycle (Crawford \& Bryce, 2003); although it rather seems that the flaws arising from failure in the earlier stages actually become evident at this stage.

Poor performance and stakeholder dissatisfaction seems to be a common rule in ID projects (Ika et al., 2012). According to Crawford and Bruce (Crawford \& Bryce, 2003), the LFA faces the following main problems: (1) absence of a time frame for implementation of activities; (2) inadequate verifiable efficiency indicators; (3) inadequate means of verification; and (4) static logic matrix.

LFA provides no guidelines for the project leader on how the project team should be assembled. Also, it does not consider the stakeholders and their importance for the project. LFA also does not propose any other tools or techniques for managing projects except project's logical framework.

\section{Introduction of the stakeholder theory}

The stakeholder theory in management differs from the classical shareholder approach, because it proposes that managers must consider the interests of the entire social environment in which the company is located and operates, i.e. all the stakeholders in a given environment, whereas the shareholders' approach implies that it is the duty of the managers to meet the interests solely of the company owners, i.e. the shareholders.

Following the publication of the book "Strategic Management: A Stakeholder Approach" (Freeman, 1984), more than 100 scientific articles and a number of books have been published on the importance of this theory. The stakeholder theory originated from the perspective of strategic management but its application has 
spread to organizational theory, business ethics, social issues in management and sustainable development (Laplume et al., 2008).

The stakeholder theory has many applications in both theory and practice and also lays the theoretical grounds of corporate social responsibility which has become a standard in the worldwide business practice over the past decade.

As can be seen from the literature review, different authors have different views and representations of the following terms: the concept of stakeholders, model of stakeholders, management of stakeholders and theory of stakeholders. This "undefined "approach was also observed by Brummer ( Brummer , 1991). Despite the relatively solid theoretical base, the researchers of this theory are mainly focused on how the application of the stakeholder theory in management can contribute to better business results for a particular company or organization. On the other hand, there is very little literature related to the application of the stakeholder theory to project management and its impact on society as a whole.

This theory is based on the assumption that the management has to meet the expectations of all stakeholders and not just shareholders (RE \& Reed, 1983).

Review of the literature reveals several models for identification of stakeholders (Donaldson \& Preston, 1995).

When it comes to the identification of stakeholders, the most important parameter is the power and influence that stakeholders exert on the enterprise. Other parameters include : i) legitimacy and urgency of information (Mitchell et al., 1997), ii ) interest in company activities ( Johnson \& Scholes , 2001) iii ) cooperation prospects (Savage et al. , 1991) and others.

Research regarding stakeholders in the literature can be divided into five segments (Laplume et al., 2008):

- The definition of stakeholders;

- The influence of stakeholders on company performance;

- Activities and response of stakeholders to company activities;

- Activities and company response to the stakeholder activities;

- Theoretical debates.

The term "stakeholder" primarily refers to employees, customers, suppliers and governments, but it also includes various non-governmental organizations, political groups, trade organizations and others. (Figure 2).

Figure 2 shows how the Company in relation with investors, political groups, clients, non governmental organisations, employees, trade organisations, vendors and governments. The list of the stakeholders is probably more extensive which adds to the complexity of the environmet and decision-making process. However, in order to achieve manageable research environment the stakeholders have to be listed by relative importance and influence to research phenomenon. 


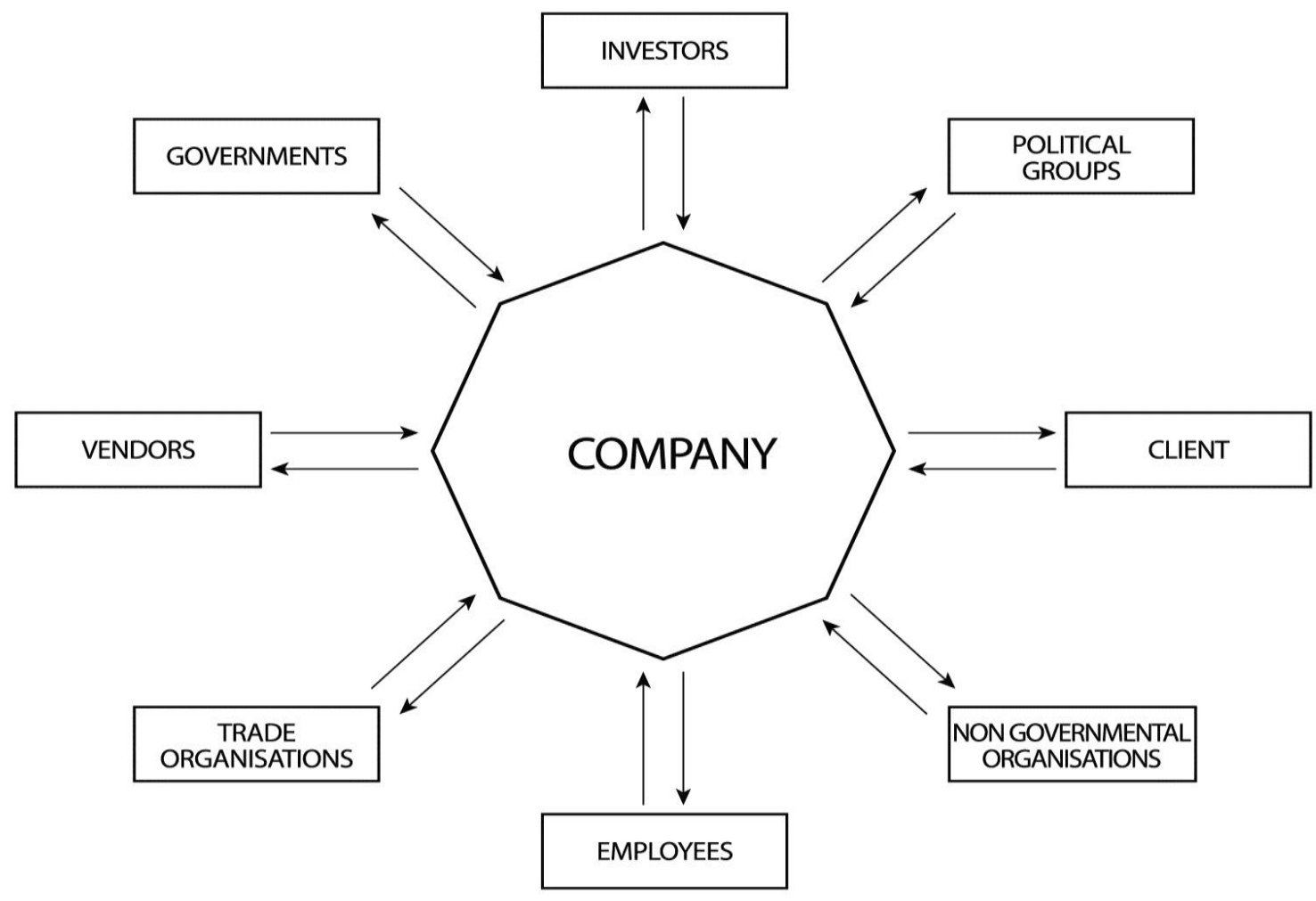

Fig. 2. Company stakeholder chart

The stakeholder theory has not yet been empirically confirmed, and except for a few special editions it is not yet included in the mainstream of research. When it comes to the stakeholder theory, the strongest public response was prompted by Tony Blair who promised to transform UK into a stakeholder society) (Robson \& Robson, 1996).

One of the central problems in the evolution of the stakeholder theory is the confusion regarding its nature and purpose. The theory has been used explicitly or implicitly for descriptive purposes only. Brenner pointed out the two-purpose theory of corporate stakeholders (Brenner \& Cochran, 1991):

- Assistance in company activities,

- Prediction of organizational behavior.

The neoclassical theory of enterprises considers the economic principles of production, investment and price definition in companies that operate in competitive markets (Cyert \& March, 1963). Cyert's theory explains the decision-making process in relation to the goals and expectations of stakeholders. Through the Cooperative 
Game Theory of the Firm, Aoki (Aoki, 1984) attempts to explain the internal procedures, in particular the balance between ownership and labor structure.

Contrary to previous theories, the transaction cost theory attempts to explain why the organization exists (Coase, 1937) (Williamson \& Winter, 1993).

The next segment will explain the three aspects of the stakeholder theory which can be found in expert literature and the main differences between them: descriptive / empirical, instrumental and normative.

Descriptive/empirical theory is used to describe and explain the specific characteristics and patterns of business behavior. For example, stakeholder theory is used to describe (a) the nature of the enterprise (Brenner \& Cochran , 1991), (b) the manner in which managers think about leadership (Brenner \& Molander, 1977) (c) how the board of directors perceives the interests of corporate constituencies (Wang \& Dewhirst , 1992) and (d), what is the actual management system of certain enterprises (Clarkson, 1995).

Instrumental theory is used in conjunction with the descriptive / empirical aspect if possible, and serves to identify the relationship, or lack thereof between stakeholders and the achievement of strategic objectives ( profitability, economic growth, etc. . ).

Normative theory is used to interpret the function of the enterprise, including identification of moral and psychological principles of the company operation and management. Normative ethics has dominated the classical stakeholder theory from the very beginning (Dodd Jr., 1931) and the tradition continues in subsequent research (Carroll, 1991) (Kuhn \& Shriver, 1991). Even Friedman attacked the concept of social responsibility in terms of normative ethics (Friedman, 1970).

Regardless of the choice of methodology, the above studies tend to generate implications suggesting the principles of stakeholders and practices for accomplishment of company goals, better than or similar to the competition. Cotter and Hesket observed successful companies such as Hewlett - Packard, Wall -Mart and Dayton Hudson although they are very different in terms of stakeholders. Through research they came to a conclusion that almost all company executive take care of the people that have an interest in the corporate business: clients, employees, shareholders, suppliers, etc.( Kotter \& Heskett, 1992).

\section{Upgrading the project cycle management model}

Research in the scope of the article included a segment from the scientific area of project management dealing with the establishment of information society through international development funds. Through detailed examination of multiple case studies it was found that indeed international projects used by groups of countries as tools for establishing mechanisms of balanced regional development affect the establishment of information society. This is a very important information given the fact that, as was pointed out in the theoretical approach, technological development leads to constant segmentation in terms of implementation of new tools and solutions. It is necessary to set up a mechanism for continuous improvement so that the 
environment can successfully adapt to trends in roughly the same pace as other regions and environments.

At the same time there is a significant flaw in the project approach in the area of international development projects in terms of inconsistent observation of stakeholders and project beneficiaries which was ultimately confirmed by relatively low coverage, during the programming of assigned goals. This is indicated by dimensions of success such as the influence on project beneficiaries and long-term success.

When talking about the dimensions of success in the theory, it has been recognized that the project does not need to be successful in all aspects, and that is why international development projects from the IPA group (Hungary-Serbia 20072013 programme) were suitable for observation because they by nature exclude the possibility of failure on the issue of the first dimension of success - efficiency and the issue of the third dimension - business success. With regards to the first dimension, the budget and implementation deadlines are rigidly outlined, while the third dimension is bound by the constant fact that these projects are not allowed to generate profit. Results from case study reviews clearly show that it is possible to improve the project approach, i.e. the project cycle approach in the implementation of international development projects in such a way that projects influencing the establishment of information society are brought into relationship with the influence on beneficiaries and long-term impact of the project, which, as statistically demonstrated have no influence.

Analysis of the readiness on organizational and project level and the processing of 40 meticulously filled questionnaires by participants in previously finalized international development projects (which are not part of the sample analyzed using the case study method) revealed a connection between the components of project readiness, leadership, management system, competence and technology. The connection shows information society development indicators in terms of increased number of computers in organizations that implemented the projects, improved and facilitated access to the internet and other networks, increased concern for the protection of data and systems, introduction of electronic purchase transactions, and finally, increased number of functionalities in internet presentations.

The project strategy is the link between corporate strategy and project realization. International development projects also start from the strategic level, this time on state or regional level, ending with assignment of projects to various organizations (the first three phases of the project cycle). Furthermore, during project implementation, the project success can be observed, which is characteristic for the remaining two phases (implementation and evaluation ) as shown in Figure 3 on the next page.

In this figure it is possible to actually notice that the model of association of project strategy which affects the respective dimensions of project success can be applied equally well on commercial and international development projects alike, which supports the generality of the project cycle model and its implementation on projects strategy and success. 
The atricle research actually revealed that the application of the project strategy theory and stakeholder theory can actually complement the model of project cycle management and hence maximize project success, especially in terms of measurement of user satisfaction, business success and long-term impact.

It is interesting to point out that, in order to ensure project success, the implementation phase needs to be influenced through incentives for all stakeholders, in order to ensure their active involvement in the project, as well as to dynamically consider certain embedded limitations and to correct the same. In other words, the "Out- of- the- Box" theory should be applied during the implementation phase.

Figure 3 is showing division between project success and project strategy area as well as feedback link from evaluation phase to identification phase.

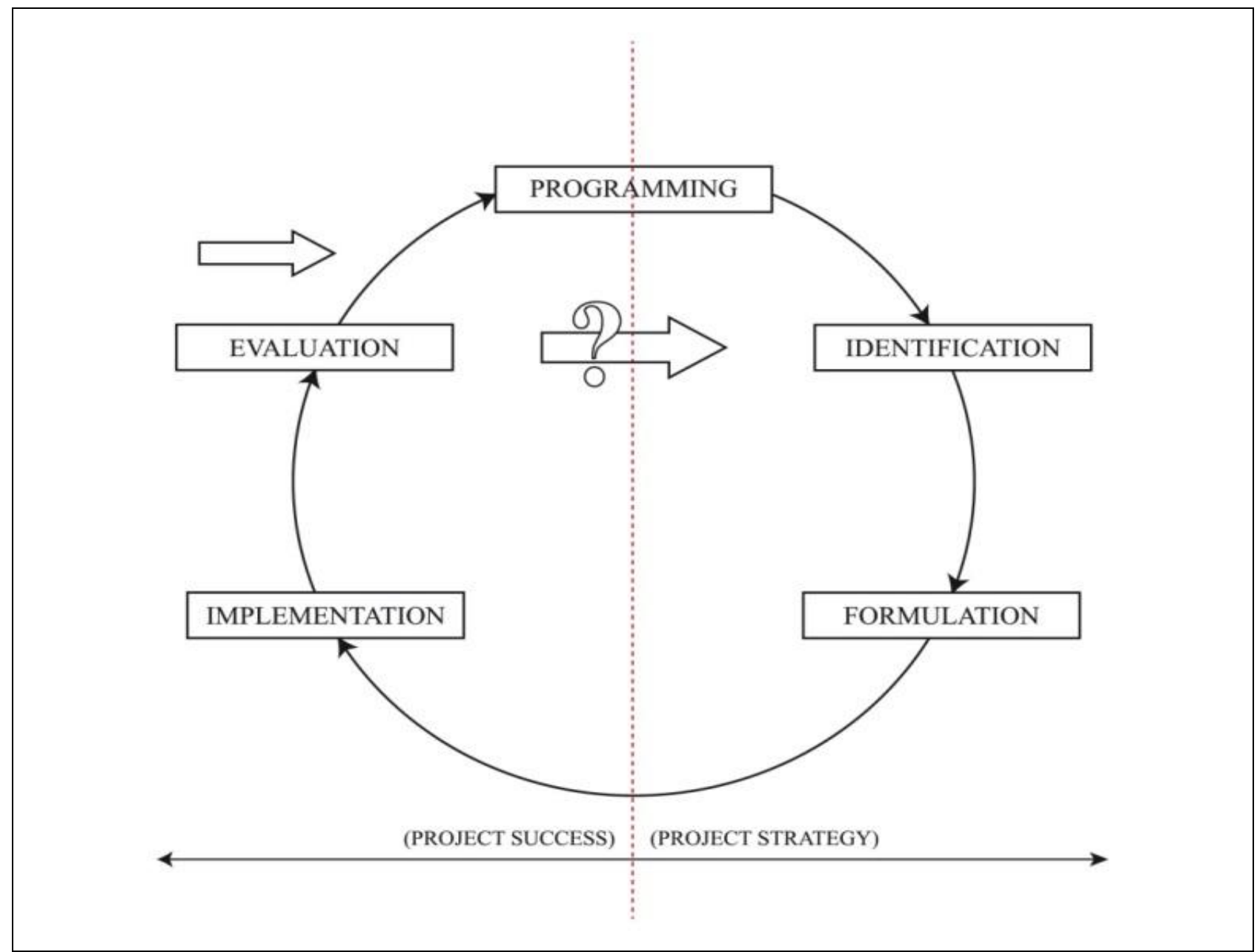

Fig. 3. Project cycle associating project strategy and success

When applying »Out-of-the-Box« theory to the model we are improving the model by using modern project management principles. This approach shall further improve the overall project results and give appropriate feedback to implementation phase. By creating feedback loop we are connecting project success and project strategy phase.

Figure 4 shows correction represented by employing a project evaluation committee which would be transformed into a project evaluation and correction committee and which would discuss the new documents, known in the field of 
commercial projects as "change request." This principle is commonly used in complex IT project and is used to manage and record changes within the project. If used in implementation phase we can manage the change process and perform early feedback action back to identification phase thus acting quickly in order to better the project outcome.

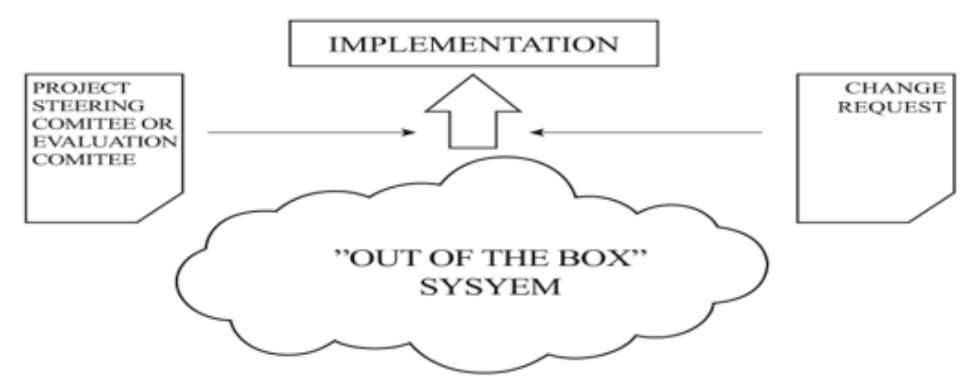

Fig. 4. "Out of the Box" approach in the implementation phase

This would achieve notable contribution of stakeholders to project success and this is exactly where the most important information for the identification phase should come from, creating early feedback loop as shown by black arrow in Figure 5.

Early feedback into the identification phase may have critical influence on the consequent project identification and formulation. This is expected to improve project funding efficiency giving early information to project cycle and shortening the time to make neccessary changes to improve results. This principle is well known in technical sciences and process automation. Strict and accurate feedback significantly improves every process where applied. It creates a field of self correcting actions that drives the process into increased efficiency.

It is iminent that complex projects have a considerable duration and especially after implementation the administrative actions may take time. It is not unusual that the period between implementation and evaluation is the longest period in the project. This increases the importance of the feedback to be delivered sooner in order to implement the neccessary corrections in the identification phase. It is also of critical importance that the identification administrative phase is supported by the project results in order not to repeat the same mistakes and that the project documentation for published project is altered. Such alterations may have significant impact to factors of project success as well as positive impact on funding effectiveness.

It is important that the funding impacts the areas where designated.

It is also necessary to incorporate the developed plan for communication with stakeholders into the updated model.

Finally, we are able to incorporate all prior findings into an upgraded Multilayer Project Cycle Management (PCM) model as shown in the figure 6. 


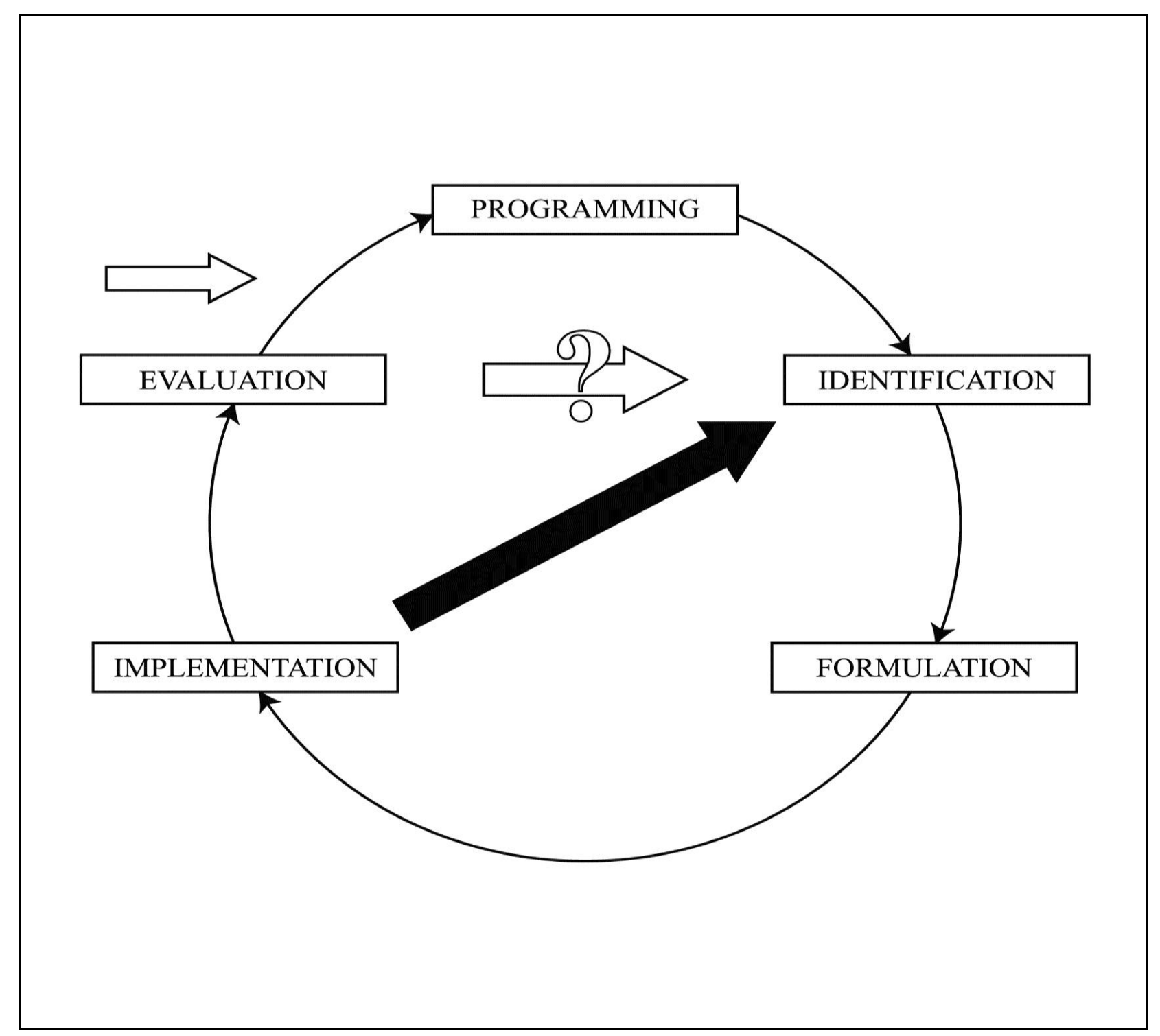

Fig. 5. Contribution of stakeholders theory in the generic model of PCM

Figure 6 compiles all research components into one complex project management methodology. Stakeholders should be taken into account as well as early feedback loop from implementation to identification phase. Analysis of stakeholders in each of the phases shall be performed and included into project management model. Stakeholders in industry, programme and project shall be shortlisted and consulted deep into implementation phase. In the same time the impact on stakeholders should be evaluated and followed through implementation and evaluation phase. The results must be communicated to programming phase and shall have impact on the programming documentation and defining of the funding strategies for future funding programmes.

Proposed Multi-layer Project Cycle management model is improved management model that adds modern »feedback and correct « principle charted as arrows from implementation and evaluation phase to identification phase (Kafol, 2013). 


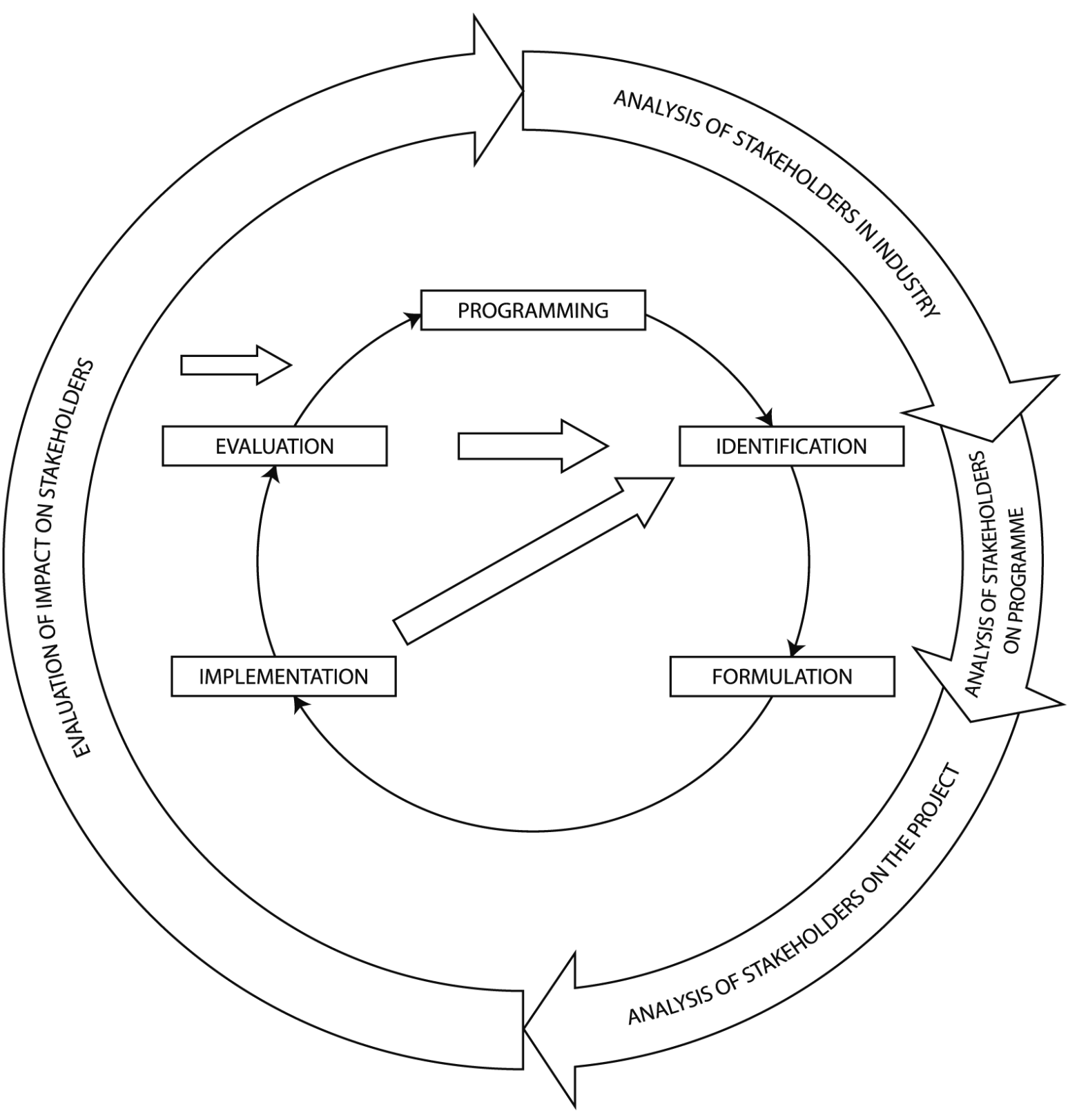

Fig. 6. Multi-layer project cycle management model

Findings from later phases are inserted into defining new project criteria through »out-of-the box « approach including change management or change request scheme. Outer circle represents inclusion of the staholders theory and analysis of the relevant stakeholders to ensure the coverage of the project results and covering all stakeholder needs in all phases of the project (Kafol, 2013). This approach ensures that two important elements: project findings and project influence to stakeholders are well addressed and implemented.

Project findings and staheholder influence are key factors to project success.

Multy-layer approach adds to the complexity of the logical framework model but it is essential for the improvement of the project management method.

We may add several other layers to the model that tend to improve the project efficiency. However transparency and usability of the model shall be taken into account 


\section{Conclusion}

Today innovations occur in the open space of the global network, without any geographical limitations. Innovations that happen exponentially lead to dramatic changes. The speed of these changes is great and presents a new challenge in the development of society. The tool which society uses in order to utilize this speed of innovative development for its own advancement is - the project (Kafol, 2013).

By programming development in line with the strategies of the region and the countries within that region, society shapes the direction it will assume in the future. These programmed directions are strategically outlined, but they need to be more closely aligned with the real needs of the region. This process of alignment is defined as identification of the actual needs and represents another phase of the project cycle.

In the period preceding the article's research, project cycle management underwent certain changes in terms of reduction of the number of phases, correction of accompanying processes etc. Research into the project success and in particular the long-term impact of implemented projects reveals that according to certain criteria the projects cannot be considered very successful, despite what the reports following project completion state.

This project management upgrade provides the project cycle with a more consistent methodology and a verifiable satisfaction of the target groups with implemented projects and their outcome. Final result is proprosed Multi-layer Project Cycle Management (PCM) model that improves the project management approach.

The article indicated the weaknesses and the necessity for improvement in the field of management international development projects, particularly in the area of information society and offered an improved model of project cycle management, which according to the author can be fully generalized and applicable in other project approach areas, in a balanced regional development.

The perception of the scientific field of project management has changed throughout the years. Initially, companies could choose whether to deal with project management or not, whereas today the only question is how successful will the company be in project management. One of the factors influencing the distinction between average vs. excellent company is the measurement of project success. Project complexity is forcing organizations to better identify, select, and measure the project success criteria.

Complex projects require flexible management due to the frequent changes in outcomes and stakeholder demands. The main difference compared to traditional projects concerns the management, degree of risk, number of stakeholders as well as project duration. While traditional projects usually last approximately 18 months, complex projects can take longer than 10 years. Because of the project length, the assumptions formulated during project initiation will almost certainly change in the course of the project. Changes may also affect the measurements of success, technology and project scope, which affects project delivery. Examples of changes in the assumptions of complex projects mostly include bank loans, procurement costs, 
technological development, availability of qualified resources, good product placement on the market, competition, risks and political environment.

The growing complexity of projects leads to a growing complexity in the number of stakeholders. A common problem in the communication with stakeholders is the differentiation of methodologies during project implementation.

Revisions to the initial plan and adjustment to new circumstances, as well as decision- making focused on project's end value will be the main prerequisites for success of future projects.

Management of complex projects necessitates a flexible and responsive methodology (Kafol, 2013). Achievement of project values is more important than satisfying the triple constraints (cost, schedule and scope).

The Report by PMI's Pulse of the Profession, conducting annual global research anticipates 15.7 million new project management job posts worldwide by 2020, without enough trained professionals who could fill them. In such conditions, companies must find ways to retain employees that provide them with competitive advantage. In the future, skills, degrees, location, etc will lose their significance. All this will lead to even more virtual and fluid teams which can be moved between projects. The next challenge will be integration of these employees into teams.

Integration, as a project leadership skill will be even more pronounced in the future. (Project Management Institute, 2013).

Further research may continue with the inclusion of the role of project members and teams into the management model as well as adding extra layers into the model to continue to enhance the results.

\section{Acknowledgments}

This article multiple case study research was made within my doctoral thesis and based on IPA programme Hungary-Serbia 2007-2013. I sincerely thank honorable Zvonko Kremljak, $\mathrm{Ph} \mathrm{D}$ for his continous support and guidance in academic area.

\section{References}

Biggs, S., \& Smith, S. (2003). A paradox of learning in project cycle management. World Development, Vol 31, Pg. 1743-1757

Brummer, J. J. (1991). Corporate responsibility and legitimacy: An interdisciplinary analysis. Greenwood Press New York

Brenner, Steven N, \& Molander, E. A. (1977). Is the ethics of business changing? Harvard Business Review, 55(1), 57-71

Brenner, S. N., \& Cochran, P. (1991). The stakeholder theory of the firm:Implications for business and society theory and research. Paper presented at the annual meeting of the International Association for Business and Society, Sundance, UT. (p. 452)

Carroll, A. B. (1991). The pyramid of corporate social responsibility: toward the moral management of organizational stakeholders. Business horizons, 34(4), 39-48 
Clarkson, M. E. (1995). A stakeholder framework for analyzing and evaluating corporate social performance. Academy of management review, 20(1), 92-117

Crawford, P., \& Bryce, P. (2003). Project monitoring and evaluation: a method for enhancing the efficiency and effectiveness of aid project implementation. International Journal of Project Management , 21 (5), 363-373

Dodd Jr, E. M. (1931). For whom are corporate managers trustees. Harv. L. Rev., 45, 1145

Donaldson, T., \& Preston, L. E. (1995). The stakeholder theory of the corporation: concepts, evidence, and implications, 20(1), 65-91

European Commission. (2003). Project Cycle Management Training Handbook. From:EuropeanCommission:

http://www.cfcu.gov.tr/SPOs/TOOLs/PCM_Training_Handbook.pdf

Freeman, R. E. (1984). Strategic management: A stakeholder approach (Vol. 1). Pitman Boston

Friedman, M. (1970). The social responsibility of business is to increase its profits. New York times magazine, 13(1970), 32-33

Ika, L., Diallo, A., \& Thuillier, D. (2012). Critical success factors for World Bank projects: an empirical investigation. International Journal of Project Management , 30 (1), 105-116

Johnson G. \& Scholes, K., (2001). Exploring public sector strategy. Pearson Education

Kafol, C. (2013). Doctoral thesis. Project support to establishing information society. Faculty of technical sciences, Novi Sad, Republic of Serbia

Kerzner, H. (2006). Project Management. Hoboken: John Wiley \& Sons

Kotter, J. P., \& Heskett, J. (1992). Corporate Culture and Performance. Corporate culture and performance. New York: Free Press

Kuhn, J. W., \& Shriver, D. W. (1991). Beyond success: Corporations and their critics in the 1990s. Oxford University Press New York

Lalic, B. (2011). Prilog istraživanju uslova za razvoj inteligentnih preduzeća. (Contribution to the study of conditions for the development of intelligent enterprises.) Novi Sad, Hoboken, Maribor, Markovac: Fakultet tehničkih nauka (Faculty of technical sciences), Novi Sad

Lalić, B., \& Marjanović, U. (2011). Level of preparedness of SMEs. In M. M. CruzCunha,\& J. Varajão, E-Business Issues, Challenges and Opportunities for SMEs: Driving Competitiveness. Lisbon, Portugal: IGI Global Publisher

Laplume, A. O., Sonpar, K., \& Litz, R. A. (2008). Stakeholder theory: Reviewing a theory that moves us. Journal of management, 34(6), 1152-1189

Milosevic, D., \& Srivannaboon, S. (2006). Theoretical framework for aligning project management with business strategy. Project Management Journal , Vol. 37, No, 3.98-110

Mirabile, R. (1997). Everything you wanted to know about competency modelling.Training and Development , 51 (8), 73-99 
Mitchell, R. K., Agle, B. R., \& Wood, D. J. (1997). Toward a theory of stakeholder identification and salience: Defining the principle of who and what really counts. Academy of management review, 853-886

Moore, M. H. (1995). Creating public value: Strategic management in government. Harvard university press

Nicholas, J., \& Steyn, H. (2008). Project Management for Business, Engineering and Technology. Oxford: Butterworth-Heinemann, Elsevier

Noland, J., \& Phillips, R. (2010). Stakeholder Engagement, Discourse Ethics and Strategic Management. International Journal of Management Reviews, 12(1), 3949.doi:10.1111/j.1468-2370.2009.00279.x

Palazzo, G., \& Scherer, A. G. (2006). Corporate Legitimacy as Deliberation: A Communicative Framework. Journal of Business Ethics, 66(1), 7188.doi:10.1007/s10551-006-9044-2

PMBOK. (2013). A guide to the project management body of knowledge (PMBOK guide) fifth edition (Vol. 2). Project Management Institute

Project Management Institute. (2010). Project Management Body of Knowledge PMBOK fourth edition, serbian translation. Novi Sad: Fakultet tehničkih nauka, (Faculty of technical sciences)

Project Management Institute. (2013). PMI's Pulse of the Profession ${ }^{\mathrm{TM}}$ The High Cost of Low Performance. Project Management Institute

Rab, A. (2009). Information Society Policies. Annual World Report 2009. World Wide: UNESCO

RE, F. R. E. R., \& Reed, D. L. (1983). Stockholders and stakeholders: A new perspective in corporate governance. California management review, 25, 88-106 Robson, J., \& Robson, I. (1996). From shareholders to stakeholders: critical issues for tourism marketers. Tourism Management, 17(7), 533-540

Savage, G. T., Nix, T. W., Whitehead, C. J., \& Blair, J. D. (1991). Strategies for assessing and managing organizational stakeholders. The executive, 5(2), 61-75

Technopolis. (2002). Final Report for the Thematic Evaluation of the Information Society. Retrieved 2012 September from European commision: ec.europa.eu

Yin, R. K. (2011). Applications of case study research. SAGE Publications, Incorporated

Wang, J., \& Dewhirst, H. D. (1992). Boards of directors and stakeholder orientation.Journal of Business Ethics, 11(2), 115-123

Wysocki, R. (2009). Effective Project Management. Indianapolis: Wiley Publishing Zakhem, A. (2007). Stakeholder Management Capability: A DiscourseTheoreticalApproach. Journal of Business Ethics, 79(4), 395-405. doi:10.1007/s10551-007-9405-5

Zaza, N. L. H. (2011). On outsourcing and offshoring: Challenges facing management and engineering PhD thesis 18 . 2011 DTU Management Engineering. DTU Management Engineering

Zelenović, D. (2011). Inteligentno provređivanje (Intelligent Enterprising) Novi Sad: Prometej 